\begin{tabular}{lllllllllllllllllllllllllllllllll}
\hline$R$ & $E$ & $V$ & I & S & T & A & D & E & E & S & T & U & D & I & O & S & I & N & T & E & R & N & A & C & I & O & N & A & L & E & S
\end{tabular}

\title{
Magíster en Estudios Internacionales
}

Con la aplicación de una estructura totalmente renovada, que apunta a poner los estudios de posgrado en Relaciones Internacionales al alcance del mayor número posible de personas -sin por ello reducir la riqueza del contenido ni las exigencias académicas- el Instituto de Estudios Internacionales inicia este año un nuevo ciclo de su programa de magíster en estudios internacionales.

Para obtener el grado de Magíster, el postulante deberá completar 240 créditos en cuatro semestres. Durante los tres primeros, deberá cumplir con un plan de estudios y en el cuarto y último, deberá preparar la tesis de grado y rendir el examen correspondiente. Esta innovación tiene por objeto lograr que el alumno complete el ciclo y egrese tras obtener el diploma correspondiente, evitando así la prolongación del trámite.

Otra innovación importante, de carácter práctico, es que los cursos se impartirán en horario vespertino, ampliando así las posibilidades de postulantes que trabajen. La idea es que los alumnos vayan definiendo cuanto antes el tema sobre el cual posteriormente prepararán su tesis. Estas favorables perspectivas se han traducido ya en un significativo aumento del número de alumnos, ya que en esta oportunidad hay más de cuarenta postulantes ( 28 chilenos y 16 extranjeros) que iniciaron en el mes de marzo sus actividades académicas.

El plan de estudios contempla dos semestres de ciencia política, dos de relaciones internacionales, dos de derecho internacional, dos de metodología, uno de relaciones económicas internacionales, uno de organizaciones internacionales y solución de controversias, uno de cooperación y organizaciones internacionales, uno sobre seguridad, uno sobre política comparada de 
Magíster en

Estudios

Internacionales

América Latina y política exterior de Chile, uno de negociaciones internacionales y uno de economía política global. El último semestre comprende un seminario temático, en que el alumno determina el propósito de su investigación a partir de la profundización de un área temática en el campo de las relaciones internacionales; un curso de investigación avanzada, que versará sobre la aplicación de las distintas técnicas y métodos de investigación al trabajo de tesis para obtener el grado de Magíster, y un seminario de tesis. La tesis es un trabajo individual que consiste en un ensayo teórico, investigación empírica, análisis histórico u otra forma de aproximación al conocimiento científico, sobre un tema propio del área interdisciplinaria de estudios internacionales. Debe reflejar la formación general recibida por el candidato en el Instituto, de acuerdo con el pluralismo teórico y metodológico propio de toda actividad académica. Una vez aprobada por las instancias correspondientes, la tesis deberá ser defendida públicamente en el examen de grado, posibilitando la graduación del alumno al término del cuarto semestre.

Los alumnos que cumplan los estudios regulares del programa de Magíster, esto es, tres semestres, y no continúen con el plan de estudios conducentes a la preparación y defensa de tesis podrán optar a un Diploma de Especialización en Relaciones Internacionales. Para acceder a esta opción, los alumnos deberán cumplir con una exigencia curricular adicional consistente en un examen sobre dos temas que forman parte de las disciplinas básicas que comprende el Programa, en una fase escrita y una oral.

En opinión del Instituto de Estudios Internacionales, y a juzgar por el interés que ha despertado la nueva modalidad, tendrá en breve un efecto multiplicador en la capacitación de profesionales interesados en profundizar sus conocimientos y acceder a nuevas posibilidades de trabajo en su especialidad. 